\title{
Are communications about work outside regular working hours associated with work- to-family conflict, psychological distress and sleep problems?
}

\author{
Scott Schieman and Marisa C. Young \\ Version Post-Print/Accepted Manuscript \\ Citation Schieman, Scott and Marisa Young. 2013. "Are Communications about \\ (published version) Work Outside Regular Working Hours Associated with Work-to-Family \\ Conflict, Psychological Distress and Sleep Problems?” Work \& Stress: \\ An International Journal of Work, Health \& Organisations 27:3:244- \\ 261.
}

Publisher's Statement This is an Accepted Manuscript of an article published by Taylor \& Francis in Work \& Stress: An International Journal of Work, Health \& Organisations on 16 July 2013, available online: http://www.tandfonline.com/10.1080/02678373.2013.817090.

How to cite TSpace items

Always cite the published version, so the author(s) will receive recognition through services that track citation counts, e.g. Scopus. If you need to cite the page number of the TSpace version (original manuscript or accepted manuscript) because you cannot access the published version, then cite the TSpace version in addition to the published version using the permanent URI (handle) found on the record page. 


\title{
Is Work Contact Associated with Psychological Distress and Sleep Problems? The Role of Communicating about Work outside Regular Working Hours
}

\begin{abstract}
Is work contact — the frequency of sending and receiving work-related communications outside of regular work hours - associated with psychological distress and sleep problems? Using data from the 2011 Canadian Work, Stress, and Health Study, a large national sample of working adults, we document that work contact is associated with higher levels of work-to-family conflict, distress, and sleep problems. In addition, with the Job Demands-Resources model as a guiding framework, we find support for the "resource hypothesis"- that is, job autonomy, schedule control, and challenging work weaken the positive association between work contact and either distress or sleep problems. By contrast, and consistent with the "demand hypothesis," job pressure exacerbates the positive association between work contact and sleep problems. Elevated levels of work-to-family conflict contribute to these interaction effects. Collectively, our findings elaborate on the complex consequences of work contact and underscore the relevance of job resources, demands, and the work-family interface in these processes.
\end{abstract}




\section{Is Work Contact Associated with Psychological Distress and Sleep Problems? The Role of Communicating about Work outside Regular Working Hours}

\section{Introduction}

"Work contact" is shorthand for the frequency that workers send and receive workrelated communications (e.g., emails, phone calls, text messages) outside of regular working hours (Schieman \& Glavin, 2008; Voydanoff, 2007). The integration of communication technologies in many workplaces has spawned new challenges for the boundaries between work and non-work life (Chesley, Moen, \& Shore, 2003). Expanded access to e-mail, cell phones, and other "Blackberry-like" tools often enhance flexibility and enable remote work, but also contribute to a " $24 / 7$ availability" that may present new stressors and strains (Batt \& Valcour, 2003; Chesley, 2005). These tools facilitate tasks outside the traditional physical and temporal parameters of the workplace, thus allowing work to intrude upon and gain primacy over other domains (Boswell \& Olson-Buchanan, 2007; Valcour \& Hunter, 2005). As border theory suggests, work contact represents a "boundary-spanning demand" that blurs the temporal, physical, and psychological boundaries that separate work and non-work life (Clark, 2000; Voydanoff, 2007). This boundary-spanning demand is distinct from — but intricately related tosome of the more conventional indicators of job-related demands like long work hours and excessive pressures (Glavin \& Schieman, 2012; Schieman \& Glavin, 2008).

What is the association between work contact and health? In this paper, we expand upon prior research by examining the consequences of work contact for two important outcomes: psychological distress and sleep problems. We then apply and extend the Job DemandsResources (JD-R) model by assessing the factors that modify those associations and the potential relevance of work-to-family conflict (WFC) as a contributing influence in these processes. To address these objectives, we analyze data from a large, nationally representative survey of 
Canadian workers - the 2011 Canadian Work Stress and Health study (CAN-WSH). These data are ideal for our objectives because they include individuals from a broad range of occupations, job sectors, and varying levels of job-related demands and resources.

\section{Work Contact and its Consequences}

To frame our argument about the potential consequences of work contact, we draw on the ideas of border theory because of its insights about the ways that individuals construct and navigate the parameters between work and home (Clark, 2000). One of its core assumptions is that workers are motivated to manage the border between work and non-work in ways that contribute to a sense of balance-which, in turn, yields higher levels of satisfaction and better role functioning. Work contact, however, represents a "boundary-spanning demand" that can challenge the parameters that separate work from the other domains of everyday life (Schieman \& Glavin, 2008; Voydanoff, 2007). In this regard, it can be characterized as a potential stressor.

High permeability — the degree to which aspects of one domain are able to enter other domains - is associated with greater role blurring (Voydanoff, 2007). The spread and use of communication technologies expand permeability such that workers may become accessible “anytime, anywhere" (Lewis \& Cooper, 1999; Valcour \& Hunter, 2005). This greater permeability, in turn, may increase exposure to other stressors like WFC (Chesley, 2005;

Schieman \& Glavin, 2008; Schieman \& Young, 2010a). WFC is defined as the extent that individuals perceive that work interferes with the responsibilities and expectations of family, and competes for individuals' finite amounts of time and energy (Greenhaus \& Parasuraman, 1987). WFC occurs when role-related pressures that emanate from the work domain are incompatible 
with and potential undermine family-related role quality and performance (Greenhaus \& Beutell, 1985).

Work contact may be problematic for the work-family interface when it is unexpected or unrelated to the context in which the individual finds himself or herself. For example, receiving communications about work might require one to quickly switch from a family or leisure frame of mind back to the "worker mindset." These role-blurring processes have the potential to represent interruptions that can generate strain and distress, especially when they challenge individuals' role or task performance in other domains (Ashforth, Kreiner, \& Fugate, 2000; Olson-Buchanan \& Boswell, 2006). Ultimately, some of the negative consequences of frequent work contact may be due to problems associated with these interruptions and their implications for self-control, depletion of resources, and feelings of exhaustion (Freeman \& Muraven, 2010; Muraven \& Baumeister, 2000; Sonnentag, Binnewies, \& Mojza, 2010; Sonnentag \& Fritz, 2007). Collectively, these ideas underscore the importance of the interference aspects of roleblurring activities and how these processes could represent problematic demands. Some prior research bolsters these claims by documenting a positive association between work contact and WFC (Schieman \& Glavin, 2008; Schieman \& Young, 2010a; Voydanoff, 2005), as well as the deleterious health consequences of WFC (Glavin, Schieman, \& Reid, 2011; Voydanoff, 2007). To our knowledge, however, no studies have applied the JD-R model's propositions about job resources and demands as moderators in the associations between work contact and both distress and sleep problems or explicitly tested WFC as a potential mediator in these interrelationships. Few studies of the work-nonwork interface consider sleep problems despite evidence of a robust connection (Chatzitheochari \& Arber, 2009; Maume, Sebastion, \& Bardo, 2009). 


\section{An Application and Extension of the JD-R Model}

The JD-R model provides a guiding framework for articulating the ways that job attributes_ — often characterized as "resources" and "demands"—-might be associated with a range of personal, social, and organizational outcomes (Bakker \& Demerouti, 2007; Demerouti, Bakker, Nachreiner, \& Schaufeli, 2001; Schaufeli \& Bakker, 2004). The JD-R model identifies resources as involving the physical, psychosocial, and organizational elements of work that foster the adequate completion of responsibilities (Bakker \& Geurts, 2004). One of its core propositions identifies a multiplicative model in which job resources purportedly undermine the negative consequences of job demands (Bakker \& Demerouti, 2007; Bakker, Demerouti, \& Euwema, 2005; Demerouti et al., 2001). Most analyses of this hypothesized interaction effect has focused on "psychological strains" as outcomes - that is, attitudes (e.g., satisfaction), behavioral intentions (e.g., absenteeism, turnover), or health (Beehr, Glaser, Canali, \& Wallwey, 2001). While research demonstrates that the levels and interactions of demands and resources often influence well-being (Hakanen, Schaufeli, \& Ahola, 2008), conclusions about the multiplicative model remain unresolved (Beehr et al., 2001; Häusser, Mojzisch, Niesel, \& Schulz-Hardt, 2010).

In the present study, we apply the JD-R model to test the resource hypothesis. It states that job resources should mitigate any problematic consequences of work contact. The specific mechanisms it proposes involve motivational elements that enhance engagement and reduce cynicism - and, by extension, contribute to either intrinsic or extrinsic motivation (see Bakker \& Geurts, 2007, p. 313). Moreover, "resource" processes associated with buffering may entail the modification of perceptions or cognitions that are associated with work contact and its consequences (Kahn \& Byosserie, 1992). The JD-R model also posits that job-related resources 
might be especially relevant for the enhancement of work engagement or motivation when job demands are high (Bakker \& Geurts, 2007, p. 315). Applied here, we posit that work contact represents a potential boundary spanning demand that could amplify the relevance and utility of job-related resources - especially as they might function as buffers in the associations between work contact and levels of work-to-family conflict, distress, and sleep problems.

Job resources typically involve the nature of, and rewards from, the work itself (Bakker \& Demerouti, 2007). This view originates from the Job Demands-Control (JD-C) model and the concept of job control — that is, the "working individual's potential control over his tasks and his conduct during the working day" (Karasek, 1979, p. 289). Job autonomy, which involves the extent that individuals have the freedom to decide when, where, and how their work gets done, has been identified as one of the most salient of these resources (Tausig \& Fenwick, 2011). Similarly, schedule control entails the "temporal flexibility in work schedules" or the degree to which workers are able to select the times that they start and/or finish work (Golden, 2001). Together, job autonomy and schedule control are often viewed as highly desirable work resources, especially given their purported benefits for navigating challenges in the work-family border and minimizing inter-role conflict (Schieman \& Glavin, 2008; Voydanoff, 2007). One potential mechanism involves the ways that resources help to facilitate the achievement of specific goals or objectives (Bakker \& Geurts, 2004); these processes may, in turn, erode the "demand" elements of work contact and its complications for stress in the work-family interface and health-related problems. An additional set of mechanisms involves the ways that work contact may be more predictable, expectably, understandable, or controllable in the context of greater job resources (Kahn \& Byosserie, 1992). As Bakker and colleagues (2005) suggest, job resources like autonomy may facilitate coping with job demands by allowing greater control over 
the nature and timing of responses to them. With these plausible mechanisms as a backdrop, the resource hypothesis predicts that both job autonomy and schedule control should attenuate any positive associations between work contact and WFC, distress, and sleep problems - evidence that would support the buffering view.

Along with these two more conventional job resources, we consider another in our analyses: challenging work. Individuals with challenging work are required to keep learning new things, engage in creative activities, use their skills and abilities, and handle a variety of tasks on the job (Schieman \& Young, 2010b). This concept blends interrelated themes that researchers across disciplines have referred to with a range of terms, including "complexity," "skill variety," "non-routine work," "creative work," "skill discretion" "learning possibilities," and “opportunities for professional development” (Bakker \& Geurts, 2004; Hackman \& Oldham, 1975; Karasek, 1979; Mirowsky \& Ross 2003). There are conceptual and empirical reasons for characterizing challenging work as a job resource alongside autonomy and schedule control— and including it within the framework of the resource hypothesis. For example, the concept has origins in the JD-C model's “decision latitude," which underscores the degree of skill discretion and creativity required on the job (Karasek \& Theorell, 1990; Karasek et al., 1998, p. 323; Van der Doef \& Maes, 1999). According to Voydanoff (2007), work conditions that foster creativity, skill enhancement and utilization, and problem solving represent highly salient job-related resources.

While the hypothesized buffering effects of these three job resources are straightforward, it is also essential to assess if job demands modify the impact of work contact. In this regard, highly demanding work provides a context that likely influences the nature of communication about work beyond the usual temporal parameters. According to Bakker and Geurts (2004): "Job 
demands refer to those physical, psychosocial, or organizational aspects of the job that require sustained physical and/or mental effort and are, therefore, associated with certain physiological and/or psychological costs" (p. 348). For the JD-R model, job demands are identified as potentially problematic for workers, especially in the "health impairment process" (Bakker et al., 2005; Demerouti et al., 2001).

In the present study, we focus explicitly on the subjective experience of job pressure because of its centrality in the work, stress, and health literature (Diestel \& Schmidt, 2009; Kristensen, Bjorner, Christensen, \& Borg, 2004; Tausig \& Fenwick, 2011). Workers who report higher levels of job pressure tend to feel overwhelmed by the amount of work they have to do, they have to work on too many tasks at the same time, and report that the demands of their job exceed the time they have to do the work. Job pressure is a subjective perception that is linked to objective conditions in the workplace (Tausig \& Fenwick, 2011). Moreover, these job pressures often increase the sense of greater time and energy commitments, which, in turn, are linked to burnout and distress (Hakanen et al., 2008), as well as exhaustion and sleep problems (see Bakker \& Demerouti, 2007, p. 309).

There are several plausible reasons for the hypothesis that contact is more detrimental in the context of high job pressure. One potential mechanism entails the degree that simultaneous exposure to high pressure and contact heightens arousal that, in turn, poses a greater threat to one's sense of equilibrium, energy, and mental or physical resources than either one does on its own (Bakker \& Geurts, 2007; Demerouti et al. 2001). A second reason why job pressure might exacerbate the impact of work contact involves the ways that both pressure and contact—as different, but interrelated demands_-draw on the same limited volitional resource (for similar arguments, see Diestel \& Schmidt, 2009; Kehr, 2004). Thirdly, Sonnentag and colleagues (2010) 
underscore the importance of psychological detachment as a means toward recovery from high levels of job pressure: "It implies that one is not working at home and not thinking about jobrelated issues, problems, or opportunities during after-work hours. In everyday life, psychological detachment from work is experienced as 'switching off' and means leaving the workplace temporarily behind oneself in physical and in mental terms" (p. 965). Frequent communications about work outside of the usual temporal parameters, however, might pose a challenge to psychological detachment and recovery from excessive job pressures; that is, it might be more difficult to "switch off" if one must frequently respond to work-related communications outside of regular work hours. In fact, this process may provide one of the primary channels for the facilitation of excessive demands. Collectively, these ideas and potential mechanisms provide a backdrop for the demand hypothesis: Work contact in the context of pressure may be more problematic for WFC, distress, and sleep problems; that is, they may have synergistic effects such that high levels of one amplifies the other's negative impact.

\section{Method}

\section{Sample}

To test the hypotheses outlined above, we analyze data from the 2011 Canadian Work Stress and Health study (CAN-WSH), a nationally representative sample of the Canadian labour force. Interviews were conducted by telephone between January and August 2011. To be eligible to participate in the study, individuals had to be: (1) residing in Canada; (2) 18 years of age or older; (3) currently working at a paid job or operated an income-producing business; (4) employed in the civilian labor force; and 5) live in a non-institutional residence. In households with more than one eligible person, we used the "next birthday" method to randomly select a 
study participant. Participation was completely voluntary. Calls were made to a regionally stratified unclustered random probability sample generated by random-digit-dial methods. Interviews were conducted in English or French and averaged approximately 30-35 minutes. Study participants received a $\$ 20$ gift card for completing the interview. The final full sample was 6,004 , with a response rate of approximately 40 percent. For the analyses in this paper, we exclude cases with missing values on the focal study variables and weight all analyses according to the most recent Canadian Census information on the gender, age, marital status, and education profile of the population. This yields an effective sample size of 5,729 with the following characteristics: 48 percent are women; the average age is 40 years; 48 percent are married or living with a partner; 40 percent have children younger than age 18 living in the household; 18 percent have a high school degree or GED and another 35 percent are college graduates; 53 percent work in a private for-profit business; 27 percent are professionals; the average weekly work hours is 38 ; and the median personal income is $\$ 41,000$.

\section{Focal Measures}

Work contact. We use three items to assess the frequency of work contact. Each item asks study participants about the following experiences in the last three months: "How often were you called about work-related matters when you were not at work?" "How often did you read jobrelated email or text messages when you were not at work?" "How often did you contact people about work-related matters when you were not at work?" Response choices are coded as follows: “never" (1), "rarely" (2), "sometimes" (3), "often" (4), and "very often" (5). We averaged the items to create the index; higher scores indicate more frequent work contact $(\alpha=.78)$. 
Work-to-family conflict. We use four items to measure WFC. These are standard items that have been used in several recent surveys, including the National Survey of the Changing Workforce and are widely published (Schieman \& Glavin, 2011; Schieman \& Young, 2010a, 2010b; Voydanoff, 2007). The items ask study participants how often in the last three months they have experienced the following: "not had enough time for the important people in your life because of your job," "not have the energy to do things with the important people in your life because of your job," "work kept you from doing as good a job at home as you could," and "job kept you from concentrating on important things in your family or personal life." Response choices are "very often" (1), "often" (2), "sometimes" (3), "rarely" (4), and "never" (5). We reverse-coded and averaged items such that higher scores indicate more WFC $(\alpha=.90)$.

Psychological distress. We use seven well-known items of generalized psychological distress adapted from the Kessler index (K10; Kessler, 2002). These items ask about the frequency that participants have experienced the following symptoms in the past month: "anxious or tense," "nervous," "worry a lot about little things," "had trouble keeping your mind on what you were doing," "restless or fidgety," "sad or depressed," and "hopeless." Response choices are "all of the time" (1), "most of the time" (2), "some of the time" (3), "a little of the time" (4), and "none of the time" (5). We reverse-coded responses and averaged them to create the index; higher scores indicate more distress $(\alpha=.83)$.

Sleep problems. We use three items to measure sleep problems (Maume et al., 2009). The items ask about the past month: "how often did you have trouble falling or staying asleep," "how often did you wake up before you wanted to," and "how often did you wake up feeling refreshed" (reverse-coded). Response choices are coded as follows: "none of the time" (1), "a 
little of the time" (2), "some of the time" (3), "most of the time" (4), and "all of the time" (5).

We averaged the items to create the index; higher scores indicate more sleep problems $(\alpha=.72)$.

Job autonomy. We use three items to assess job autonomy. Participants are asked the extent that they agree or disagree with the following statements: "I have the freedom to decide what I do on my job," "It is basically my own responsibility to decide how my job gets done," and "I have a lot of say about what happens on my job." Response choices are coded "strongly disagree" (1), "somewhat disagree" (2), "somewhat agree" (3), and "strongly agree” (4). We averaged responses to create the index; higher scores reflect more job autonomy $(\alpha=.78)$. The items used to measure job autonomy, schedule control, challenging work, and job pressures are similar or identical to those in the 2008 National Study of the Changing Workforce (NSCW).

Schedule control. We use one item to measure schedule control: "How much control do you have in scheduling your work hours?" We classified participants in three comparison groups, contrasting individuals who reported "none" or "very little" (low schedule control) with those who reported "some" or "a lot" (moderate) or "complete control" (high schedule control).

Challenging work. Five items measure challenging work: "My job requires that I keep learning new things," "My job requires that I be creative," "My job lets me use my skills and abilities," "The work I do on my job is meaningful to me," and "I get to do a lot of different things on my job" (Schieman \& Young 2010b). These items blend interrelated themes that scholars have variously referred to as "creative work," "non-routine work," "skill utilization," "learning possibilities," or “opportunities for professional development” (Bakker \& Geurts, 2004; Bakker et al., 2003; Hackman \& Oldham, 1975; Karasek et al. 1998; Mirowsky \& Ross, 2003). Response choices are coded "strongly disagree" (1), "somewhat disagree" (2), "somewhat 
agree" (3), and "strongly agree" (4). We averaged the responses to create the index; higher scores reflect more challenging work $(\alpha=.78)$.

Job pressure. We use items similar to those used in other previously published research on similar themes like "pressure," "workload," or "quantitative demands" (Carayon, \& Zijlstra, 1999; Harmä, 2006; Karasek et al. 1998; Kristensen et al., 2004). Items ask about the frequency of the following experiences in the past three months: "How often did you feel overwhelmed by how much you had to do at work?" "How often did you have to work on too many tasks at the same time?" "How often did the demands of your job exceeded the time you have to do the work?” Response choices are coded: “never” (1), "rarely” (2), “sometimes” (3), “often” (4), and "very often" (5). We averaged the items to create the index; higher scores indicate more job pressure $(\alpha=.85)$.

Table 1 reports summary statistics for the focal variables. Confirmatory factor analyses demonstrate that each of the work-related items load distinctly on their respective constructs. All analyses control for gender, age, marital status, children at home, province of residence, education, personal income, occupation, job sector, work hours, work shift, and work location. (Full CFA results and coding details about the control measures are available upon request.)

\section{[Insert table 1 about here]}

\section{Plan of Analyses}

First and foremost, we expect that individuals who experience more frequent work contact will also tend to experience more distress and sleep problems. As noted above, the resource hypothesis predicts that job resources should attenuate those associations. By contrast, the demand hypothesis predicts that job pressure should exacerbate them. In addition, we also hypothesize that WFC is an explanatory mechanism in these associations. To test our 
hypotheses, we use ordinary least squares (OLS) regression techniques and present our findings into two inter-related parts. In the first section, we assess the association between work contact and levels of WFC. In Table 2, model 1 regresses WFC on work contact (adjusting for all control variables). Model 2 includes job resources and pressure to assess the net association between contact and WFC. Models 3-6 test a series of interactions in which we multiplied work contact by the job resources and pressure. (Prior to creating these interaction terms, we centered variables.) Then we turn to work contact's association with distress (Table 4) and sleep problems (Table 5) - and test whether or not resources and job pressure function as moderators. The steps in the first section provide a backdrop for the steps in the second section, which also assess if WFC mediates any observed interactions between work contact and job resources or pressure.

\section{Results}

Work-to-family conflict. As shown in model 1 of Table 2, work contact is associated positively with WFC. In model 2, each job resource is associated negatively with WFC. Conversely, job pressure is associated positively with WFC. The positive association between work contact and WFC remains relatively stable net of each of these job attributes. In our tests of interaction effects, the positive association between work contact and WFC is attenuated by job autonomy (model 3), schedule control (model 4), and challenging work (model 5). By contrast, the positive association between contact and WFC is exacerbated by job pressure (model 6). We conducted F-tests to assess change in the $R^{2}$ for interaction models relative to the base model. These tests confirm that each of the interaction terms significantly improve the fit of the model $\left(\mathrm{F}_{\text {model } 3}=15.04, \mathrm{p}<.001 ; \mathrm{F}_{\text {model } 4}=9.17, \mathrm{p}<.01 ; \mathrm{F}_{\text {model }}=8.95, \mathrm{p}<.01 ; \mathrm{F}_{\text {model } 6}=7.54, \mathrm{p}<.01\right)$. To illustrate two of these interactions, Figure 1 illustrates that the positive association between 
work contact and WFC is weaker among those with more job autonomy. (Patterns for schedule control and challenging work are similar and therefore not illustrated.) By contrast, Figure 2 shows that greater job pressure exacerbates the positive association between work contact and WFC.

\section{[Insert table 2 and figures 1 and 2 about here]}

Distress. Model 1 of Table 3 shows that work contact is associated positively with distress. In model 2, each job resource is associated negatively with distress, while job pressure is related to more distress. Moreover, the relationship between work contact and distress holds net of these job attributes. For interaction effects, we observe only one statistically significant interaction: Schedule control (model 4a) attenuates the positive association between work contact and distress. Supplementary analyses confirm that this interaction improves model fit $\left(\mathrm{F}_{\text {model } 4 \mathrm{a}}=5.37, \mathrm{p}<.05\right)$. In addition, the inclusion of WFC - which itself is associated with greater distress - reduces the interaction effect to non-significance (model 4b). A Sobel test indicates that WFC has significant mediating influence (Sobel $\mathrm{t}_{\text {model } 4 \mathrm{a} ; 4 \mathrm{~b}}=-2.97, \mathrm{p}<.01$ ).

\section{[Insert table 3 about here]}

Sleep Problems. Model 1 of Table 4 shows that work contact is associated with more sleep problems. In model 2, each job resource is associated with fewer sleep problems, while job pressure is associated with more sleep problems. Moreover, the relationship between work contact and sleep problems holds net of these job attributes. In addition, job autonomy (model 3a) and challenging work (model 5a) attenuate the positive association between work contact and sleep problems; however, schedule control (model 4a) does not. Conversely, job pressure (model 6a) exacerbates the positive association. We find improved model fit with the inclusion of interaction terms for autonomy $\left(\mathrm{F}_{\text {model } 3 \mathrm{a}}=11.10, \mathrm{p}<.01\right)$, challenging work $\left(\mathrm{F}_{\text {model }} \mathrm{a}=7.68, \mathrm{p}<\right.$ 
$.01)$ and pressure $\left(\mathrm{F}_{\text {model } 6 \mathrm{a}}=6.78, \mathrm{p}<.01\right)$. To illustrate one of these interactions, Figure 3 shows the ways that challenging work buffers against the positive association between work contact and sleep problems. Lastly, the inclusion of WFC — which is associated with more sleep problemsreduces the interaction effects - and only the contact-by-autonomy term remains statistically significant (see models $3 \mathrm{~b}, 5 \mathrm{~b}$, and $6 \mathrm{~b}$ ). A series of Sobel tests confirm statistically significant mediating effects $\left(\mathrm{t}_{\text {model } 3 \mathrm{a} ; 3 \mathrm{~b}}=-3.80, \mathrm{p}<.01 ; \mathrm{t}_{\text {model } 5 \mathrm{a} ; 5 \mathrm{~b}}=-2.87, \mathrm{p}<.01 ; \mathrm{t}_{\text {model } 6 \mathrm{a} ; 6 \mathrm{~b}}=2.75, \mathrm{p}<.01\right)$.

\section{[Insert table 4 and figure 3 about here]}

\section{Discussion}

Is work contact problematic? In analyses of a large, nationally representative sample of Canadian workers, we identify three main contributions from our study: (1) individuals who experience more frequent work contact also tend to experience higher levels of WFC, psychological distress, and sleep problems; (2) in the relationship between work contact and WFC, job resources tend to attenuate the positive association, while job pressure tends to exacerbate it; and (3) to varying degrees, job resources buffer the association between work contact and both distress and sleep problems - but the patterns are not uniform, differ somewhat across these two outcomes, and are largely attributable to differences in exposure to WFC. Collectively, our efforts provide an application and extension of the JD-R model.

Several observations are consistent with the resource hypothesis. First and foremost, all three of the job resources function as moderators for WFC. Specifically, the positive association between work contact and WFC is significantly weaker among workers who have more autonomy, schedule control, and challenging work. It is worth underscoring here that challenging work functions as a moderator like the other more conventional job resources; this pattern therefore reinforces the characterization of challenging work as a "job resource." Thus, 
work contact that occurs in the context of a job that requires learning new things, engaging in creative tasks, and using skills and abilities is less problematic for the work-family interface.

It is noteworthy that the different job-related resources have somewhat different moderating effects - that is, contact that occurs in these different contexts seems to have differing patterns of association with WFC, distress, and sleep problems. For example, both job autonomy and challenging work have similar moderating functions for two of the three focal associations: WFC and sleep problems. By contrast, schedule control attenuates the positive association between work contact and WFC and distress - but not the link between contact and sleep problems. These divergent patterns are somewhat surprising and underscore the importance of considering different resources and outcomes in research on stress in the work-family interface. At this early stage of our research, we are uncertain about the specific reasons for these different patterns. One point of speculation about schedule control, for example, is as follows: Because of the flexibility and type of control it affords, schedule control might be a more practical and effective resource for neutralizing interruptions and therefore help minimize the extent that work contact is disruptive. These processes may be more closely related to feelings of anxiety and worry. Conversely, having greater autonomy and challenging work may minimize the extent that work contact "keeps one up at night" ruminating on work problems. Establishing a basis for these kinds of nuances, however, requires more in-depth analyses of underlying processes and meanings. In this effort, a planned qualitative component of the present study will directly build upon these preliminary findings and seek to elaborate on them in detail.

In addition to our observations of buffering effects for the job resources, another contribution of our study involves the ways that job pressure consistently exacerbates the positive association between work contact and the different outcomes. As others have 
documented, job pressure is related to more frequent work contact (Schieman \& Glavin, 2008). We expand upon that previous research by demonstrating that work contact is even more problematic when it occurs in a context where workers feel overwhelmed by the amount of work that they have to do, when they are required to work on too many tasks at the same time, and when the demands of their job exceeded the time that they have to do the work. In other words: High-pressured work contexts intensify the connection between work contact and WFC or sleep problems. In some ways, these findings provide an extension of the JD-R model by revealing the ways that one type of job demand - pressure - amplifies the problematic aspects of what Voydanoff (2007) has identified as a central "boundary spanning demand"—work contact.

Moreover, our analyses also depict the ways that WFC contributes to the interaction effects for work contact and these job characteristics. We detected three inter-related patterns that contribute to these effects. First, people with more WFC tend to have more distress and sleep problems. Second, each of the job resources attenuates the positive association between work contact and WFC. Taking these patterns into account helps explain why, to varying degrees, the job resources and job pressure moderate the positive associations between work contact and both distress and sleep problems. These interrelationships suggest that WFC is a potentially critical mediating mechanism.

Despite these contributions, we wish to acknowledge several study limitations. First and foremost, these findings are based on analyses of cross-sectional data. This presents some limits to our claims about causal ordering. However, it does not necessarily suggest that the patterns do not reflect some of the processes or mechanisms in workers' experiences. One way we might reflect on this limitation involves how closely our modeling approach seeks to map on to the conceptual and theoretical ideas about the interrelationships among these job conditions. It is 
directly linked to the theoretical case and personal narratives that people use when they describe the nature of their work and the consequent stressors or demands embedded in those arrangements. Nonetheless, we recognize that some part of the causal associations among resources, demands, and distress or sleep may occur in a different direction (de Lange, Taris, Kompier, Houtman, \& Bongers, 2004). Another concern about cross-sectional data involves the influence of selection effects. The data analyzed here are from the first wave of a proposed multi-wave effort. We anticipate the capacity in future additional waves of data to better establish causal ordering and the influence of selection effects. The present study should therefore be viewed as a preliminary baseline set of ideas and estimates that require further validation with the anticipated longitudinal data. Moreover, as we mentioned above, a supplemental qualitative component that involves in-depth interviews with a broad cross-section of these same study participants will help us to elaborate more fully on the meanings and appraisals of the processes we have sought to articulate here.

To conclude, we document that workers who frequently send and receive work communications outside of regular work hours tend to report more WFC, psychological distress, and sleep problems. Three job-related resources-autonomy, schedule control, and challenging work — weaken the link between contact and WFC—and, to varying degrees, also buffer against the link with distress or sleep problems. Importantly, however, we have also demonstrated that job pressure has an amplifying influence, providing a context in which work contact has even greater detrimental consequences. And, finally, WFC either partially or fully mediates these interaction effects. Collectively, these observations provide the preliminary steps that shed new light on a growing phenomenon — work contact—and the relevance of job-related demands and resources for its consequences personal and role functioning. 


\section{References}

Ashforth, B. E., Kreiner, G. E., \& Fugate, M. (2000). All in a day's work: Boundaries and micro role transitions. Academy of Management Review, 25, 472-491.

Bakker, A. B. \& Demerouti, E. (2007). The job-demands-resources model: State of the art. Journal of Managerial Psychology, 22, 309-328.

Bakker, A. B. \& Geurts, S. A. E. (2004). Toward a dual-process model of work-home interference. Work and Occupations, 31, 345-366.

Bakker, A. B., Demerouti, E., \& Euwema, M. C. (2005). Job resources buffer the impact of job demands on burnout. Journal of Occupational Health Psychology, 10, 170-180.

Batt, R. \& Valcour, P. M. (2003). Human resources practices as predictors of work-family outcomes and employee turnover. Industrial Relations, 42, 189-220.

Beehr, T. A., Glaser, K. M., Canali, K. G., \& Wallwey, D. A. (2001). Back to basics: Reexamination of demand control theory of occupational stress. Work \& Stress, 15, 115-130.

Boswell, W. R. \& Olson-Buchanan, J. B. (2007). The use of communication technologies after hours: The role of work attitudes and work-life conflict. Journal of Management, 33, 592610.

Carayon, P. \& Zijlstra, F. R. H. (1999). Relationship between job control, work pressure and strain: Studies in the USA and the Netherlands. Work \& Stress, 13, 32-48.

Chatzitheochari, S. \& Arber, S. (2009). Lack of sleep, work and the long hours culture: Evidence from the UK Time Use Survey. Work, Employment, and Society, 23, 30-48.

Chelsey, N. (2005). Blurring boundaries? Linking technology use, spillover, individual distress, and family satisfaction. Journal of Marriage and Family, 67, 1237-1248. 
Chesley, N., Moen, P., \& Shore, R. P. (2003). The new technology climate: Work and family in the information age. In P. Moen (Ed.), It's about time: Couples'strategies, strains, and successes (pp. 220-241). Cornell: Cornell University Press.

Clark, S. C. (2000). Work/family border theory: A new theory of work/family balance. Human Relations, 53, 747-770.

De Lange, A. H., Taris, T. W., Kompier, M. A., Houtman, I. L., \& Bongers, P. M. (2004). The relationships between work characteristics and mental health: Examining normal, reversed and reciprocal relationships in a 4-wave study. Work \& Stress, 18, 149-166.

Demerouti, E., Bakker, A. B., Nachreiner, F., \& Schaufeli, W. B. (2001). The job demandsresources model of burnout. Journal of Applied Psychology, 86, 499-512.

Demerouti, E., Bakker, A. B., de Jonge, J., Janssen, P. P., \& Schaufeli, W. B. (2001). Burnout and engagement at work as a function of demands and control. Scandinavian Journal of Work, Environment and Health, 27, 279-86.

Diestel, S. \& Schmidt, K. H. (2009). Mediator and moderator effects of demands on self-control in the relationship between work load and indicators of job strain. Work \& Stress, 23, 6079.

Freeman, N., \& Muraven, N. (2010). Don't interrupt me! Task interruption depletes the self's limited resources. Motivation and Emotion, 34, 230-241.

Glavin, P. \& Schieman, S. (2012). Work-family role blurring and work-family conflict: The moderating influence of job resources and job demands. Work \& Occupations, 39, 71-98.

Glavin, P., Schieman, S., \& Reid, S. (2011). Boundary-spanning work demands and their consequences for guilt and psychological distress. Journal of Health and Social Behavior, 52, 43-57. 
Golden, L. (2001). Flexible work schedules: Which workers get them? American Behavioral Scientist, 44, 1157-1178.

Greenhaus, J. H. \& Beutell, N. J. (1985). Sources of conflict between work and family roles. Academy of Management Review, 10, 76-88.

Greenhaus, J. H. \& Parasuraman, S. (1987). A work-nonwork interactive perspective of stress and its consequences. Journal of Organizational Behavior Management, 8, 37-60.

Hackman, J. R., \& Oldham, G. R. (1975). Development of the job diagnostic survey. Journal of Applied Psychology, 60, 159-170.

Hakanen, J., Schaufeli, W. B., \& Ahola, K. (2008). The job demands-resources model: A threeyear cross-lagged study of burnout, depression, commitment, and work engagement. Work \& Stress, 22, 224-241.

Harmä, M. (2006). Work hours in relation to work stress, recovery and health. Scandinavian Journal of Work Environment Health, 32, 502-514.

Häusser, J. A., Mojzisch, A., Niesel, M., \& Schulz-Hardt, S. (2010). Ten years on: A review of recent research on the Job Demand-Control (-Support) model and psychological wellbeing. Work \& Stress, 24, 1-35.

Kahn, R. L. \& Byosserie, P. (1992). Stress in organizations. In M. D. Dunette \& L. M. Hough (Eds), Handbook of industrial and organizational psychology (pp. 571-650). Vol. 3. $2^{\text {nd }}$ edition. Palo Alto, CA: Consulting Psychologists Press.

Karasek, R. \& Theorell, T. (1990). Healthy work: Stress, productivity, and the reconstruction of working life. New York, NY: Basic Books.

Karasek, R. (1979). Job demands, job decision latitude, and mental strain: Implications for job redesign. Administrative Science Quarterly, 24, 285-308. 
Karasek, R., Brisson, C., Kawakami, N., Houtman, I., Bongers, P., \& Amick, B. (1998). The job content questionnaire (JQC): An instrument for internationally comparative assessments of psychosocial job characteristics. Journal of Occupational Health Psychology, 3, 322-355.

Kehr, H. M. (2004). Implicit/explicit motive discrepancies and volitional depletion among managers. Personality and Social Psychology Bulletin, 30, 315-327.

Kessler, R. C. (2002). The categorical versus dimensional assessment controversy in the sociology of mental illness. Journal of Health and Social Behavior, 43, 171-188.

Kristensen, T. S., Bjorner, J. B., Christensen, K. B., \& Borg, V. (2004). The distinction between work pace and working hours in the measurement of quantitative demands at work. Work \& Stress, 18, 305-322.

Lewis, S, \& Cooper, C. (1999). The work-family research agenda in changing contexts. Journal of Occupational Health Psychology, 4, 382-393.

Maume, D. J., Sebastian, R. A., Bardo, A. R. (2009). Gender differences in sleep disruption among retail food workers. American Sociological Review, 74, 989-1007.

Mirowsky, J. \& Ross, C. E. (2003). Social causes of psychological distress (2 ${ }^{\text {nd }}$ edition). New York: Aldine De Gruyter.

Muraven, M. \& Baumeister, R. F. (2000). Self-regulation and depletion of limited resources: Does self-control resemble a muscle? Psychological Bulletin, 126, 247-259.

Olson-Buchanan, J. B. \& Boswell, W. R. (2006). Blurring boundaries: Correlates of integration and segmentation between work and nonwork. Journal of Vocational Behavior, 68, 432445. 
Schaufeli, W. B. \& Bakker, A. B. (2004). Job demands, job resources and their relationship with burnout and engagement: A multi-sample study. Journal of Organizational Behavior, 25, 293-315.

Schieman, S. \& Glavin, P. (2008). Trouble at the border? Gender, flexible work conditions, and the work-home interface. Social Problems, 55, 590-611.

Schieman, S. \& Glavin, P. (2011). Education and work-family conflict: Explanations, contingencies, and mental health consequences. Social Forces, 89, 1341-1362.

Schieman, S. \& Young, M. (2010a). Is there a downside to schedule control for the work-family interface? Journal of Family Issues, 31, 1391-1414.

Schieman, S. \& Young, M. (2010b). The demands of creative work: Implications for the stress in the work-family interface. Social Science Research, 39, 246-259.

Sonnentag, S. \& Fritz, C. (2007). The recovery experience questionnaire: Development and validation of a measure for assessing recuperation and unwinding from work. Journal of Occupational Health Psychology, 12, 204-221.

Sonnentag, S., Binnewies, C., \& Mojza, E. J. (2010). Staying well and engaged when demands are high: The role of psychological detachment. Journal of Applied Psychology, 95, 965976.

Tausig, M. \& Fenwick, R. (2011). Work and Mental Health in Social Context. New York, NY: Springer.

Valcour, P. M. \& Hunter, L. W. (2005). Technology, organizations, and work-life integration. In E. Kossek, \& S. J. Lambert (Eds.), Work and life integration: Organizational, cultural, and individual perspectives (pp. 61-85). Mahwah, NJ: Lawrence Erlbaum Associates. 
Van der Doef, M. \& Maes, S. (1999). The job demand-control (-support) model and psychological well-being: A review of 20 years of empirical research. Work \& Stress, 13, 87-114.

Voydanoff, P. (2007). Work, family, and community: Exploring interconnections. Mahwah, NJ: Routledge Publishing. 
TABLE 1. Means, Standard Deviations, and Correlations between Focal Variables $(N=5,729)$

\begin{tabular}{|c|c|c|c|c|c|c|c|c|c|c|}
\hline & & 1 & 2 & 3 & 4 & 5 & 6 & 7 & 8 & 9 \\
\hline 1 & WFC & - & & & & & & & & \\
\hline 2 & Distress & .41 & - & & & & & & & \\
\hline 3 & Sleep & .33 & .48 & - & & & & & & \\
\hline 4 & Work contact & .34 & .11 & .09 & - & & & & & \\
\hline 5 & Autonomy & -.13 & -.20 & -.15 & .22 & - & & & & \\
\hline 6 & Some control & -.03 & -.04 & -.06 & .12 & .09 & - & & & \\
\hline 7 & Full control & -.13 & -.09 & -.05 & .08 & .33 & -.41 & - & & \\
\hline 8 & Challenge & -.04 & -.17 & -.13 & .22 & .47 & .04 & .16 & - & \\
\hline 9 & Job pressure & .54 & .30 & .21 & .30 & -.05 & -.01 & -.11 & .10 & - \\
\hline & $\mathrm{M}$ & 2.47 & 2.18 & 2.74 & 2.32 & 2.88 & .48 & .16 & 3.29 & 2.97 \\
\hline & SD & 1.00 & .71 & .98 & 1.07 & .81 & - & - & .68 & 1.09 \\
\hline
\end{tabular}

Note: All coefficients greater than .04 are statistically significant at the $p<.01$ level (two-tailed test). 
TABLE 2. Regression of Work-to-Family Conflict on Work Contact and Job Demands and Resources

\begin{tabular}{|c|c|c|c|c|c|c|}
\hline Variable & Model 1 & Model 2 & Model 3 & Model 4 & Model 5 & Model 6 \\
\hline Work contact & $.310 * *$ & $.214 * *$ & $.215^{* *}$ & $.265^{* *}$ & $.213 * *$ & $.209 * *$ \\
\hline \multicolumn{7}{|l|}{ Job Resources } \\
\hline Job autonomy & - & $-.099 * *$ & $-.109 * *$ & $-.098 * *$ & $-.099 * *$ & $-.098 * *$ \\
\hline Some schedule control & - & $-.134 * *$ & $-.132 * *$ & $-.149 * *$ & $-.134 * *$ & $-.132 * *$ \\
\hline Full schedule control & - & $-.219 * *$ & $-.212 * *$ & $-.224 * *$ & $-.219 * *$ & $-.217 * *$ \\
\hline Challenging work & - & $-.137 * *$ & $-.138 * *$ & $-.139 * *$ & $-.153 * *$ & $-.137 * *$ \\
\hline \multicolumn{7}{|l|}{ Job Demands } \\
\hline Job pressures & - & $.406^{* *}$ & $.405^{* *}$ & $.405^{* *}$ & $.405^{* *}$ & $.410 * *$ \\
\hline \multicolumn{7}{|l|}{ Moderating Associations } \\
\hline Autonomy x work contact & - & - & $-.060 * *$ & - & - & - \\
\hline Some control x work contact & - & - & - & -.058 & - & - \\
\hline Full control x work contact & - & - & - & $-.124 *$ & - & - \\
\hline Challenging work $\mathrm{x}$ work contact & - & - & - & & $-.065^{*}$ & - \\
\hline Job pressures $\mathrm{x}$ work contact & - & - & - & - & - & $.031 *$ \\
\hline Constant & 2.345 & 2.299 & 2.292 & 2.314 & 2.299 & 2.251 \\
\hline$R^{2}$ & .193 & .391 & .393 & .393 & .393 & .392 \\
\hline
\end{tabular}

$* p<.01 ; * * p<.001$ (two-tailed test).

Note: Unstandardized regression coefficients are presented in the table. All models control for gender, age, marital status, children at home, province of residence, education, personal income, occupation, job sector, work hours, work shift, and work location. 
TABLE 3. Regression of Psychological Distress on Work Contact and Job Demands and Resources

\begin{tabular}{|c|c|c|c|c|c|c|c|}
\hline Variable & Model 1 & Model 2 & Model 3 & Model 4a & Model 4b & Model 5 & Model 6 \\
\hline Work contact & $.117 * *$ & $.080 * *$ & $.081 * *$ & $.107 * *$ & .045 & $.080 * *$ & $.077 * *$ \\
\hline \multicolumn{8}{|l|}{ Job Resources } \\
\hline Job autonomy & - & $-.083 * *$ & $-.088 * *$ & $-.082 * *$ & $-.059 *$ & $-.082 * *$ & $-.082 * *$ \\
\hline Some schedule control & - & $-.085^{* *}$ & $-.087 * *$ & $-.097 * *$ & -.061 & $-.088 * *$ & $-.087 * *$ \\
\hline Full schedule control & - & $-.109^{*}$ & $-.106 *$ & $-.109 *$ & -.056 & $-.109 *$ & $-.109 *$ \\
\hline Challenging work & - & $-.145^{* *}$ & $-.146 * *$ & $-.147 * *$ & $-.114 * *$ & $-.147 * *$ & $-.144 * *$ \\
\hline \multicolumn{8}{|l|}{ Job Demands } \\
\hline Job pressures & - & $.197^{* *}$ & $.197 * *$ & $.197 * *$ & $.101 * *$ & $.197 * *$ & $.200 * *$ \\
\hline \multicolumn{8}{|l|}{ Interactions } \\
\hline Autonomy x contact & - & - & -.034 & - & - & - & - \\
\hline Some control $\mathrm{x}$ contact & - & - & - & -.023 & -.010 & - & - \\
\hline Full control $\mathrm{x}$ contact & - & - & - & $-.082 *$ & -.054 & - & - \\
\hline Chall. work $\mathrm{x}$ contact & - & - & - & - & - & -.010 & - \\
\hline Pressures x contact & - & - & - & - & - & - & .023 \\
\hline \multicolumn{8}{|l|}{ Work-to-Family Conflict } \\
\hline Work-to-family conflict & - & - & - & - & $.236 * *$ & - & - \\
\hline Constant & 2.219 & 2.188 & 2.184 & 2.196 & 2.245 & 2.184 & 2.184 \\
\hline$R^{2}$ & .084 & .207 & .208 & .208 & .277 & .208 & .208 \\
\hline
\end{tabular}

$* p<.01 ; * * p<.001$ (two-tailed test).

Note: Unstandardized regression coefficients are presented in the table. All models control for gender, age, marital status, children at home, province of residence, education, personal income, occupation, job sector, work hours, work shift, and work location. 
TABLE 4. Regression of Sleep Problems on Work Contact and Job Demands and Resources

\begin{tabular}{|c|c|c|c|c|c|c|c|c|c|}
\hline Variable & Model 1 & Model 2 & Model 3a & Model 3b & Model 4 & Model 5a & Model 5b & Model 6a & Model 6b \\
\hline Work contact & $.123 * *$ & $.095 * *$ & $.096^{* *}$ & .042 & $.113 * *$ & $.095^{* *}$ & .040 & $.090 * *$ & .036 \\
\hline Job autonomy & - & $-.096 * *$ & $-.107 * *$ & $-.079 *$ & $-.096 * *$ & $-.096 * *$ & $-.071 *$ & $-.095 * *$ & $-.070 *$ \\
\hline Full schedule control & - & -.060 & -.053 & .001 & -.056 & -.060 & -.004 & -.058 & -.002 \\
\hline Challenging work & - & $-.169 * *$ & $-.171 * *$ & $-.135 * *$ & $-.171 * *$ & $-.189 * *$ & $-.146 * *$ & $-.179 * *$ & $-.133 * *$ \\
\hline \multicolumn{10}{|l|}{ Job Demands } \\
\hline \multicolumn{10}{|l|}{ Interactions } \\
\hline Autonomy x contact & - & - & $-.062 *$ & $-.047 *$ & - & - & - & - & - \\
\hline Some control $\mathrm{x}$ contact & - & - & - & - & -.008 & - & - & - & - \\
\hline Full control $\mathrm{x}$ contact & - & - & - & - & -.072 & - & - & - & - \\
\hline Chall. work $\mathrm{x}$ contact & - & - & - & - & - & $-.067 *$ & -.050 & - & - \\
\hline Pressures x contact & - & - & - & - & - & - & - & $.035^{*}$ & .027 \\
\hline
\end{tabular}

Note: Unstandardized regression coefficients are presented in the table. All models control for gender, age, marital status, children at home, province of residence, education, personal income, occupation, job sector, work hours, work shift, and work location. 
FIGURE 1. The Relationship between Work Contact and Work-to-Family Conflict across Levels of Job Autonomy $(N=5,729)$

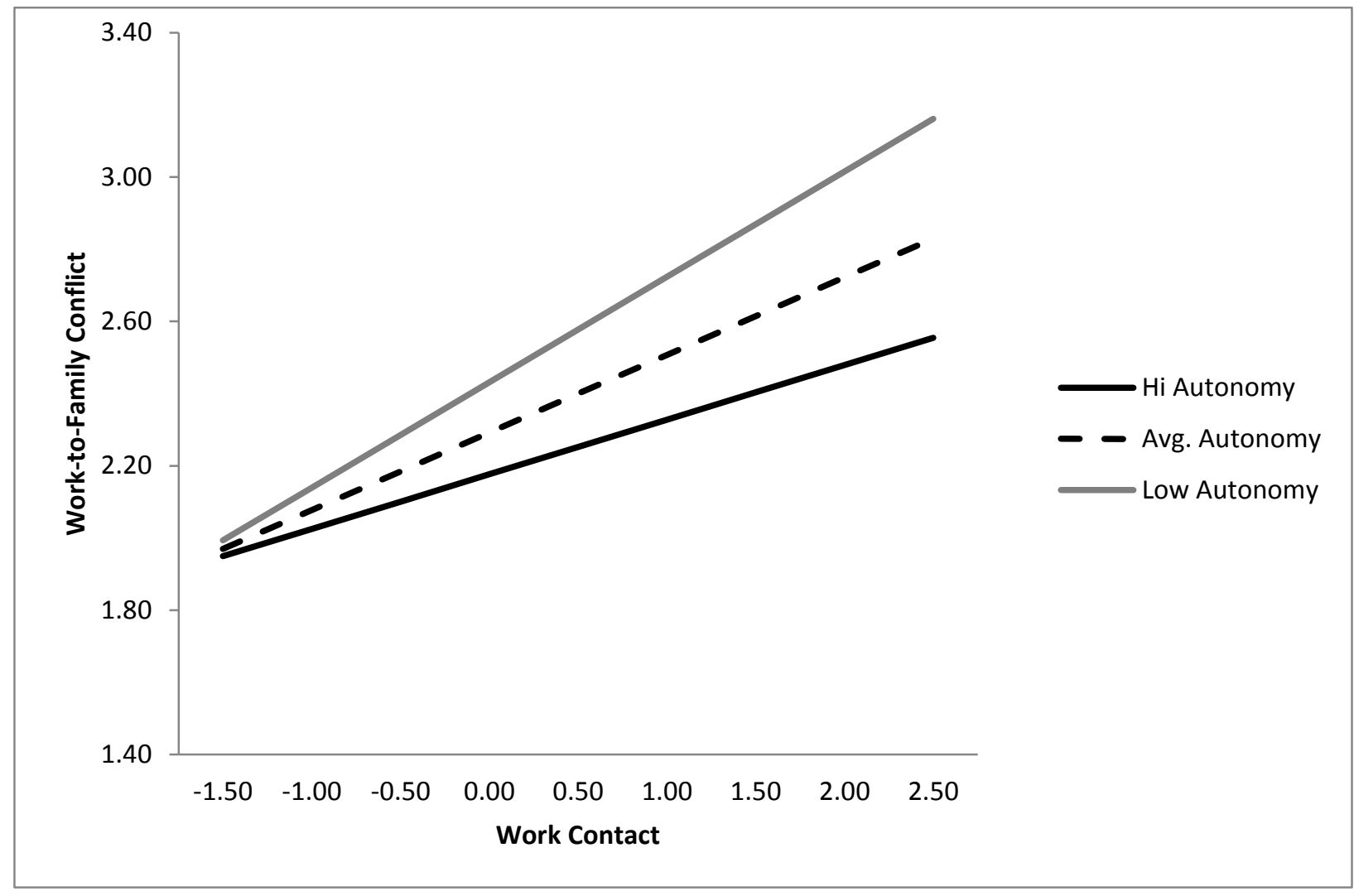

Note: Predicted values of work-to-family conflict are based on results shown in model 3 of Table

2. All values for the continuous variables are held constant at their means. We solved that equation for white, married men working 40-49 hours per week in the private sector in professional occupations with no schedule control, earning $\$ 25,000$ to $\$ 49,999$ per year. 
FIGURE 2. The Relationship between Work Contact and Work-to-Family Conflict across Levels of Job Pressures $(N=5,729)$

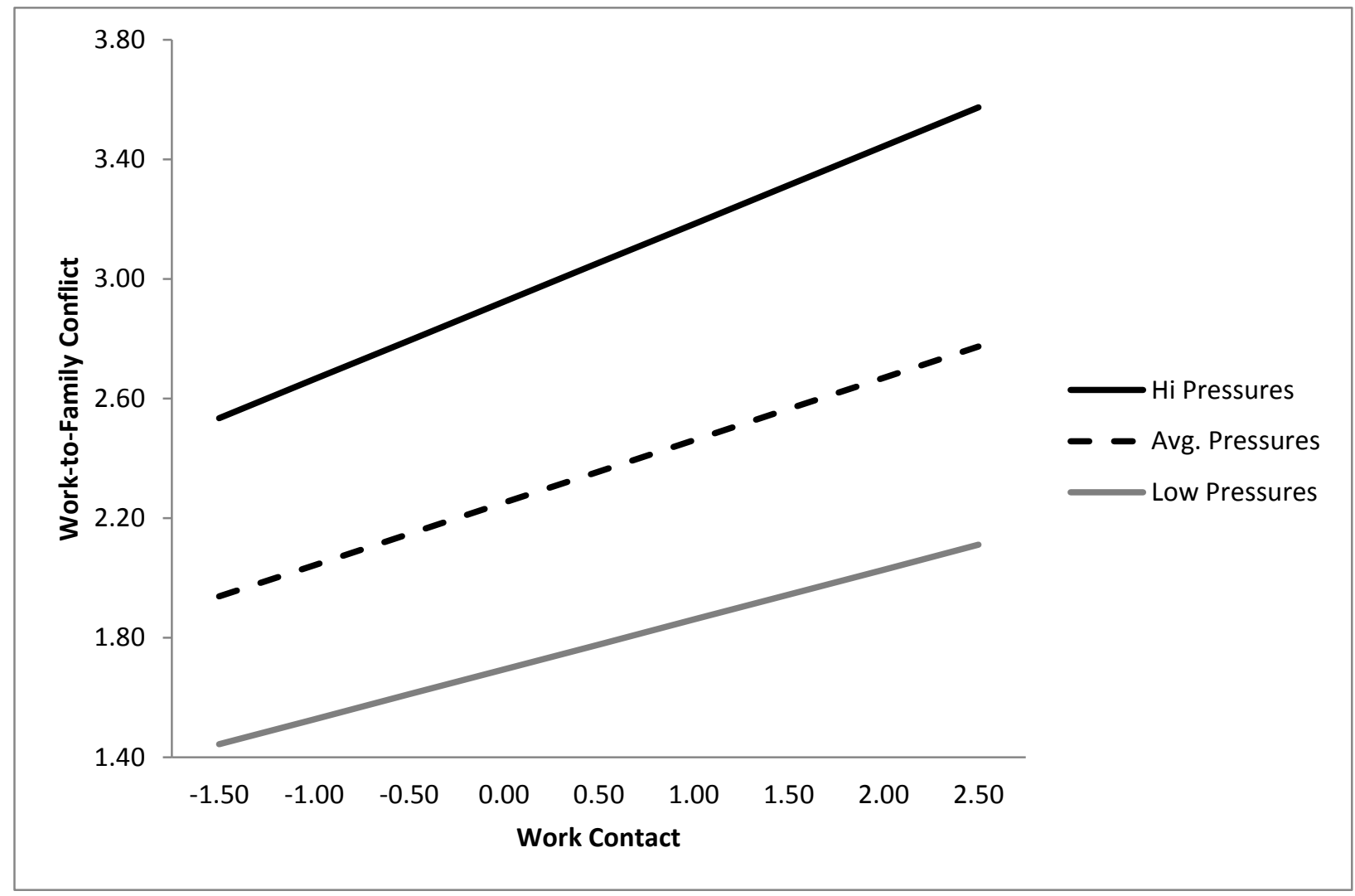

Note: Predicted values of work-to-family conflict are based on results shown in model 6 of Table

2. All values for the continuous variables are held constant at their means. We solved that equation for white, married men working 40-49 hours per week in the private sector in professional occupations with no schedule control, earning $\$ 25,000$ to $\$ 49,999$ per year. 
FIGURE 3. The Relationship between Work Contact and Sleep Problems across Levels of Challenging Work $(N=5,729)$

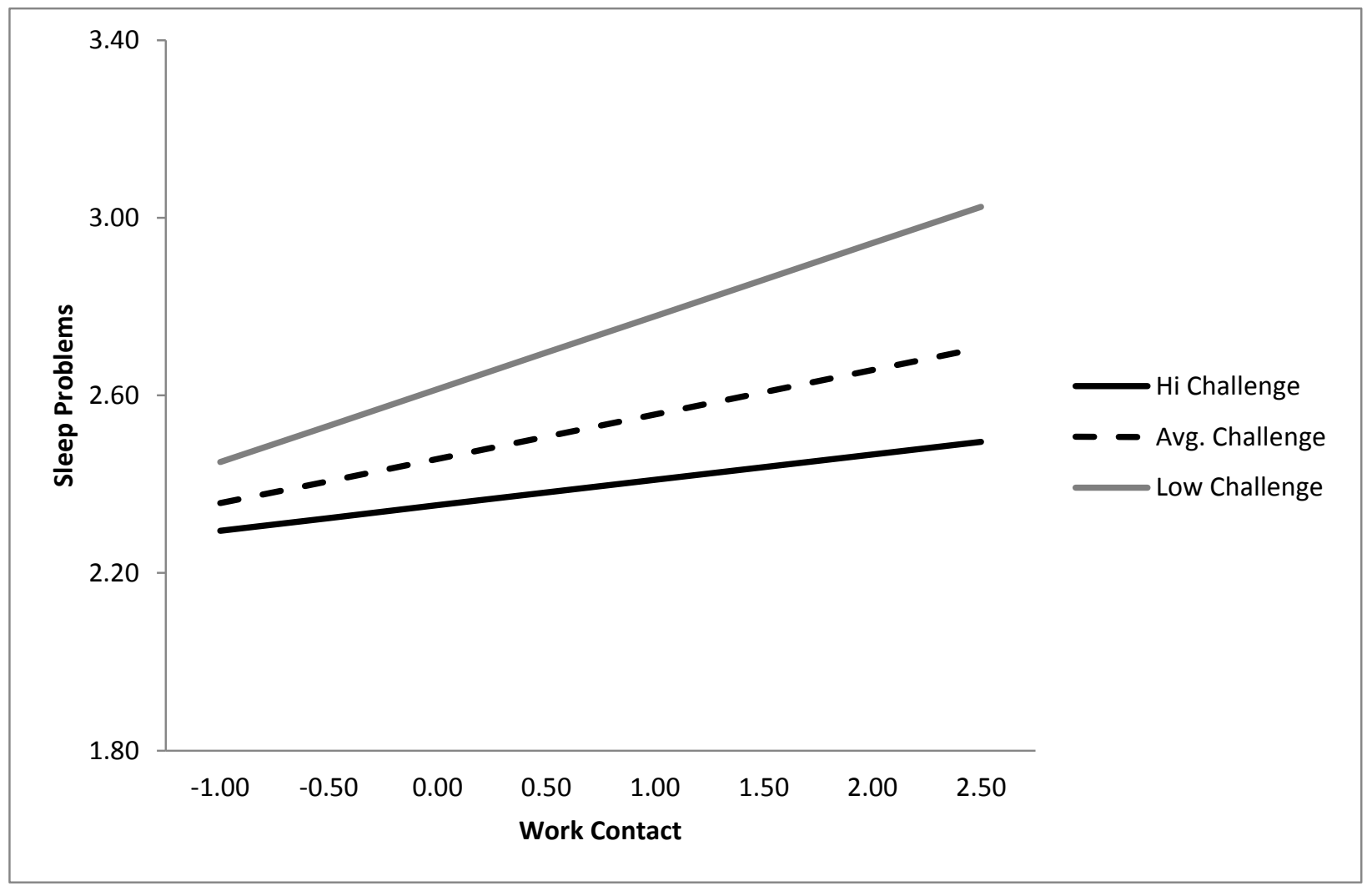

Note: Predicted values of sleep problems are based on results shown in Table 4, models 5a. All continuous values are held constant at their respective means. We solved that equation for white, married men working 40-49 hours per week in the private sector in professional occupations with no schedule control, earning $\$ 25,000$ to $\$ 49,999$ per year. 